\title{
Oferta y Demanda en Mercados Competitivos: Enfoque al Sector de la Construcción en el Ecuador.
}

\section{Supply and Demand in Competitive Markets: Focus on the Construction Sector in Ecuador.}

Omar Gabriel Mejía Flores ${ }^{1}$, Nubia Elizabeth Casquete Baidal ${ }^{2}$, Pedro Alexander Avilés Almeida $^{3}$ \& Carlos Gabriel Parrales Choez. ${ }^{4}$

DOI: https://doi.org/10.33262/visionariodigital.v3i2.396

\section{Resumen.}

El mercado de la construcción en algunas oportunidades se percibe una clara distinción o diferenciación entre las empresas y del producto que nos pueden entregar, lo indicado que es producido por la empresa, Ecuador es un país altamente vulnerable ante las crisis, varios factores son los que pesan en la economía ecuatoriana, como la excesiva dependencia de los ingresos petroleros, la dolarización. estos generan inestabilidad. El sector de la construcción crece en consonancia con el PIB, siendo un actor importante dentro de la Economía ecuatoriana. Los altos precios del petróleo le han permitido al Gobierno actual incrementar considerablemente los montos de la inversión pública (construcción de hidroeléctricas, carreteras, centros médicos, centros del buen vivir, unidades educativas del milenio, etc.) y el gasto público, especialmente el corriente. Pero lamentablemente, la bonanza petrolera llegó a su fin, pues los precios de su principal producto de exportación, logran cubrir tan solo los costos de producción.

De acuerdo al Banco Central, mantendrá una leve recuperación en los próximos años, lo cual tuvo mucho que ver la derogatoria de la Ley de Plusvalía, la promulgación de la Ley de Fomento Productivo, que crearon las condiciones de inversión y financiamiento de la economía., la promulgación de la Ley de Fomento Productivo, que crearon las condiciones de inversión y financiamiento para este sector tan importante de la economía.

Palabras claves: Oferta, Demanda, Mercado competitivos, Construcción

\footnotetext{
${ }^{1}$ Universidad de Guayaquil, Guayaquil, Ecuador, omar.mejiaf@ug.edu.ec

${ }^{2}$ Universidad de Guayaquil, Guayaquil, Ecuador, nubia.casqueteb@ug.edu.ec

${ }^{3}$ Universidad de Guayaquil, Guayaquil, Ecuador, pedro.avilesa@ug.edu.ec

${ }^{4}$ Universidad de Guayaquil, Guayaquil, Ecuador, carlos.parralesch@ug.edu.ec
} 


\begin{abstract}
.
The construction market sometimes perceives a clear distinction or differentiation between the companies and the product that can be delivered to us, as indicated by the company, Ecuador is a country highly vulnerable to crises, several factors are those that They weigh in the Ecuadorian economy, such as excessive dependence on oil revenues, dollarization. These generate instability. The construction sector grows in line with GDP, being an important player in the Ecuadorian economy. The high oil prices have allowed the current government to increase considerably the amounts of public investment (construction of hydroelectric plants, roads, medical centers, centers of good living, educational units of the millennium, etc.) and public spending, especially the current. But unfortunately, the oil bonanza came to an end, because the prices of its main export product, manage to cover only the production costs.
\end{abstract}

According to the Central Bank, it will maintain a slight recovery in the coming years, which had a lot to do with the repeal of the Goodwill Law, the enactment of the Law of Productive Development, which created the conditions for investment and financing of the economy. , the enactment of the Law of Productive Development, which created the conditions of investment and financing for this important sector of the economy.

Keywords: Supply, Demand, Competitive market, Construction.

\title{
Introducción.
}

Acorde a lo que establece la OMC, los países miembros tienen 3 tipos de medidas para la protección del comercio: medidas antidumping, compensatorias y salvaguardias. El gobierno ecuatoriano en marzo del 2015, decidió acogerse a las salvaguardias las cuales se definen como "medidas de urgencia con respecto al aumento de las importaciones de determinados productos cuando esas importaciones hayan causado o amenacen causar un daño grave a la rama de producción nacional del Miembro importador" (Organización Mundial de Comercio).

"Los principios rectores del Acuerdo con respecto a las medidas de salvaguardia son los siguientes: deberán ser temporales; sólo podrán imponerse cuando se determine que las importaciones causan o amenazan causar un daño grave a una rama de producción nacional competidora; se aplicarán (generalmente) de manera no selectiva (es decir, en régimen NMF o de la nación más favorecida); se liberalizarán progresivamente mientras estén en vigor; el Miembro que las imponga deberá (en general) dar una compensación a los Miembros cuyo comercio se vea afectado". (Organización Mundial de Comercio).

Acorde a la explicación del gobierno ecuatoriano, la medida busca equilibrar la balanza de comercial del país, afectada por la caída de los precios del petróleo y la apreciación del dólar con respecto a las monedas de los países vecinos, y de esta manera proteger a la industria nacional e impulsar el crecimiento de la matriz productiva.

En nuestro país las salvaguardias inicialmente fueron previstas por 15 meses que regían desde marzo 2015 hasta junio de 2016 a un conjunto de 2955subpartidas arancelarias con 
sobretasas con 4 niveles: 5\%, 15\%, 25\% y 45\%. En junio del 2016 fueron extendidas por un año más hasta junio de 2017, estas se aplican a 2200 partidas arancelarias con sobretasas de 3 niveles: $15 \%, 25 \%$ y $40 \%$.

La construcción es el único sector que no se recupera económicamente. Al menos es el que por 11 trimestres consecutivos ha decrecido. En el tercer trimestre del 2017 la caída fue del 8,5\%, según cifras del Banco Central del Ecuador. Aunque el sector de petróleo y minas en los tres primeros trimestres del 2017 también decreció, en el 2016 sí tuvo resultados positivos. Por lo tanto, la construcción es el 'patito feo' del Producto Interno Bruto (PIB). Aún no logra desplegar sus alas, para emprender vuelo.

La Cámara de Construcción de Guayaquil, indica que el problema se debe que la economía del país ha crecido sobre la base de la inversión que el Estado ha realizado, con recursos obtenidos con créditos, pero no sobre la base de crear actividades productivas que ayuden realmente al crecimiento económico. "Por lo cual se mantiene un escenario de desconfianza, que en el caso de la construcción es fundamental

En los últimos años podemos notar que algo está pasando con la economía a nivel mundial, pues el año 2015 fue el peor en cuanto a crecimiento económico y comercio internacional. La incertidumbre que se existió en el 2009 (recesión global) o la intranquilidad del 2012 (inestabilidad del euro) vuelve nuevamente a dominar las esferas económicas a nivel mundial.

Las previsiones del Fondo Monetario Internacional, revelan un crecimiento económico mundial cada vez más a la baja, siendo esta una constante, con perspectivas todavía más pesimistas para los años venideros. Solo se espera que surja un Keynes para que estructure una nueva teoría, que propenda a bajar los costos de producción, como un reto que ya lo vivió el capitalismo con la revolución industrial y ahora con la revolución energética norteamericana.

Estados Unidos y China se muestran como un ejemplo de pueblos organizados que tiene una capacidad de innovación, que dejó atrás a muchos países de su altura. Se planteó un reto, tener energía, y ahora tiene energía; dejando impávidos al mundo entero de cómo va ganando competitividad en el mercado, con costos de producción cada vez más a la baja. El estancamiento del comercio internacional ha sido aprovechado por las exportaciones norteamericanas, su expansión, ha puesto en crisis a los países productores de commodities, en especial el petróleo cuyo boom está llegando a su fin.

Ecuador no es la excepción, más bien es un país altamente vulnerable ante las crisis. Varios factores son los que pesan en la economía ecuatoriana, principalmente la excesiva dependencia de los ingresos petroleros y la dolarización. Ambos factores, le están situando en un precipicio, que al menor tambaleo le genera inestabilidad.

Los altos precios del petróleo le han permitido al Gobierno actual incrementar considerablemente los montos de la inversión pública (construcción de hidroeléctricas, carreteras, centros médicos, centros del buen vivir, unidades educativas del milenio, etc.) 
y el gasto público, especialmente el corriente. Pero lamentablemente, la bonanza petrolera llegó a su fin, pues los precios de su principal producto de exportación, logran cubrir tan solo los costos de producción.

La balanza de pagos del Ecuador que se mantuvo deficitaria por muchos años, pero se sostuvo por los ingresos petroleros, ahora con una situación contraria, el problema salta a la vista, para lo cual el Gobierno ha implementado medidas económicas que se presentan de manera recurrente. Una de estas medidas aplicadas son las salvaguardias arancelarias, que tienen la finalidad de regular el nivel general de importaciones $\mathrm{y}$, de esta manera equilibrar la deficitaria balanza comercial de bienes.

El mercado de la construcción en algunas oportunidades se percibe como una especie de mercado de "comodities", es decir, que no hay una clara distinción o diferenciación entre las empresas y del producto que nos pueden entregar, lo que quiere decir: el concreto producido por la empresa A es igual al concreto producido por la empresa B. Esto nos lleva en ocasiones al error de decidir sólo por el precio del producto terminado, sin tomar en consideración la forma en cómo se materializa esa disminución y el proceso o servicio ofrecido en su integridad, lo que puede significar una gran diferencia.

Lo que implica es que si en construcción compramos un producto a un precio menor de lo habitual y no existe un respaldo sustentable para justificar el menor valor, al final siempre vamos a terminar pagando lo que valía originalmente para el mercado en general $y$ en muchas ocasiones inclusive un precio mayor con otras consecuencias asociadas, tales como: incumplimiento de plazos, pérdida de imagen y, algo que se vuelve cada vez más importante, eventual impacto y reacciones de la comunidad en caso que se vea afectada por los incumplimientos.

Esto nos lleva entonces a pensar de qué forma podemos disminuir nuestros precios de manera sustentable de tal forma que efectivamente podamos justificar y respaldar una disminución. A este respecto me gustaría citar dos conceptos básicos planteados y analizados por (Michael Porter, 1998):

a) Dejando de lado las consideraciones de impuestos o financiamiento que pueden afectar la ecuación del margen en una empresa, en términos simples el margen será igual al precio de venta menos los costos.

De esta forma Porter plantea que para aumentar nuestro margen debemos diferenciarnos dentro del mercado de tal forma de poder fijar un precio mayor, o disminuir nuestros costos mediante el aumento de nuestra eficiencia, o la aplicación de ambos. Haciendo un análisis sobre la base de este planteamiento, respecto de la industria de la construcción, podríamos argumentar que si consideramos el precio como una suerte de "comodity", con poca flexibilidad, y que nuestro primer objetivo será disminuirlo, entonces deberemos enfocarnos en el margen o en los costos. Muchas empresas optan por bajar el margen, sin embargo, esto no aporta valor a la empresa sino que más bien lo destruye; por tanto, sólo nos queda la opción de mejorar nuestra eficiencia para disminuir los costos, 
otorgándonos la posibilidad de hacerlo de manera sustentable generando una ventaja competitiva.

b) Porter establece que: la competitividad radica en la posibilidad de crear valor y ser único; y no necesariamente enfocarse en ser el mejor o derrotar a la competencia. Esta idea nos lleva al concepto de colocarnos metas internas que agreguen valor, lograrlas y volver a definir nuevas metas aplicando lo que podríamos entender como el concepto Kaizen (Imai, 1986); este concepto nos introduce a una filosofía de producción que se funda en la dinámica del "Cambio para Mejor" o "Mejora Continua". Esta filosofía nos conducirá en el mediano o largo plazo a una disminución de los costos y probablemente a algún tipo de diferenciación creando una ventaja competitiva para nuestra organización.

Este es el mejor momento, para cambiar de modelo económico, a uno que propenda al resurgimiento de un nuevo país. Como lo dijo Albert Einstein

"La crisis es la mejor bendición que puede sucederle a personas y países porque la crisis trae progresos".

Ecuador debe aprovechar que le sacudieron la confortabilidad exportadora petrolera, para emprender un nuevo camino, la diversidad, que es el motor de la invención pública, puesto que genera creatividad y se convierte en la forma más viable de enriquecer al mundo entero.

El establecimiento de la dolarización como esquema monetario en el país trajo consigo la eliminación de la política monetaria la misma que es uno de los mecanismos más eficientes para afrontar a corto plazo cualquier desequilibrio externo que afecte la economía. Ante la ausencia de política monetaria y la presencia de choques externos, la política comercial se convierte en la única herramienta de respuesta.

La caída de los precios del petróleo y la devaluación de la moneda de los socios comerciales más cercanos del Ecuador generó un fuerte desbalance comercial por lo que se optó por el establecimiento de salvaguardas; medida que permite equilibrar la balanza comercial y mantener masa monetaria en el esquema de dolarización. Si bien las importaciones han registrado un comportamiento errante entre el 2014 y 2015, durante el período abril a mayo de 2015 se registró una disminución de las importaciones por US\$ 950 millones de los cuales US\$ 375 millones son fruto de la aplicación de salvaguardas. La medida en sí tuvo un importante impacto en el equilibrio de las cuentas comerciales de la nación ya que los volúmenes de importación se redujeron en $56 \%$ y los montos en $27 \%$ dentro de las partidas a las que fueron afectadas por la medida, mientras que en partidas que no entraron en el listado de la política la caída de las importaciones fue de $1.5 \%$ en volumen y en $17 \%$. Adicionalmente no se registraron cambios importantes en el comportamiento del mercado laboral en contrapartida de caída en la incidencia de pobreza por ingresos. El Gobierno comenzó a sentir la falta de dólares por la reducción del precio del petróleo, y al evidenciar que nos quedaríamos cortos en liquidez, acertadamente decidió desincentivar las importaciones, así los dólares se quedarían en el país. Muchos pensaron que el incremento en aranceles tenía como objetivo el recaudar más tributos, 
pero realmente la intención fue que, con el aumento del precio final del producto importado, la gente optara por alternativas nacionales y no salieran tantos dólares de nuestra economía.

Según Henry Yandún Presidente de la Cámara de la Construcción de Quito 2015 indica que en una construcción para el segmento medio alto y alto se determinó que el promedio del costo de la obra negra es el $35 \%$, y el costo de los acabados es de $45 \%$. Los materiales para la obra negra no se vieron afectados por las salvaguardas, de tal manera que ahí no hay incremento; pero los materiales para acabados sí tuvieron su impacto con aranceles extras de entre el $15 \%$ y el $45 \%$, es decir, $30 \%$ en promedio. De este análisis se desprende que en proyectos destinados al segmento medio alto y alto, que sí usan productos importados, la afectación en el precio final del inmueble está en el orden del 6,76\% de incremento. Si analizamos los proyectos enfocados en el segmento medio y bajo, el impacto sería del $1,58 \%$ de incremento en el precio final.

Tabla 1. Indicadores Nacionales del Número de Empresas del Sector de la Construcción.

\begin{tabular}{|l|c|c|c|c|c|c|}
\hline Tamaño de Empresa & $\mathbf{2 0 1 2}$ & $\mathbf{2 0 1 3}$ & $\mathbf{2 0 1 4}$ & $\mathbf{2 0 1 5}$ & $\mathbf{2 0 1 6}$ & $\mathbf{2 0 1 7}$ \\
\hline Microempresa & 20.721 & 24.000 & 25.473 & 25.529 & 25.039 & 25.386 \\
\hline Pequeña empresa & 3.446 & 3.860 & 3.893 & 3.894 & 3.722 & 3.604 \\
\hline Mediana empresa A & 382 & 430 & 403 & 436 & 440 & 408 \\
\hline Mediana empresa B & 230 & 282 & 286 & 261 & 256 & 267 \\
\hline Grande empresa & 157 & 197 & 188 & 178 & 183 & 164 \\
\hline \multicolumn{1}{|c|}{ Total } & $\mathbf{2 4 . 9 3 6}$ & $\mathbf{2 8 . 7 6 9}$ & $\mathbf{3 0 . 2 4 3}$ & $\mathbf{3 0 . 2 9 8}$ & $\mathbf{2 9 . 6 4 0}$ & $\mathbf{2 9 . 8 2 9}$ \\
\hline
\end{tabular}

Fuente: Directorio de Empresas y Establecimientos del INEC

Las empresas dedicadas a la construcción a nivel nacional se redujeron del 2015 al 2017 en 1,55\% todo esto debido a la aplicación de las medidas arancelarias aplicadas a algunos productos y materiales de construcción, provocando que disminuya la demanda de estos materiales.

Figura 1. Indicadores Nacionales de las Ventas en el Sector de la Construcción

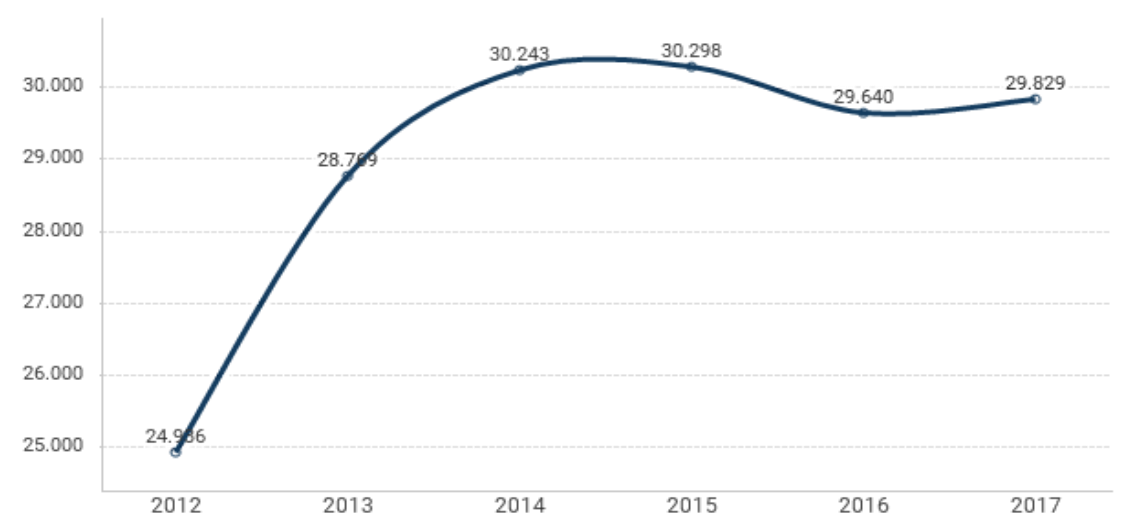


ISSN: 2602-8506

www.visionariodigital.org

Vol. 3, N², p. 143-154, abril - junio, 2019

\begin{tabular}{|l|c|c|c|c|c|c|}
\hline $\begin{array}{l}\text { Tamaño de } \\
\text { Empresa }\end{array}$ & $\mathbf{2 0 1 2}$ & $\mathbf{2 0 1 3}$ & $\mathbf{2 0 1 4}$ & $\mathbf{2 0 1 5}$ & $\mathbf{2 0 1 6}$ & $\mathbf{2 0 1 7}$ \\
\hline Grande empresa & $\$ 3.034 .262 .074,00$ & $\$ 5.000 .446 .606$ & $\$ 5.168 .750 .645$ & $\$ 4.676 .803 .701$ & $\$ 4.209 .561 .354$ & $\$ 4.162 .568 .613$ \\
\hline Pequeña empresa & $\$ 835.405 .704,00$ & $\$ 936.062 .338$ & $\$ 1.013 .755 .949$ & $\$ 981.071 .778$ & $\$ 917.266 .461$ & $\$ 893.191 .074$ \\
\hline Mediana empresa B & $\$ 640.944 .552,00$ & $\$ 793.078 .321$ & $\$ 796.904 .801$ & $\$ 731.505 .334$ & $\$ 699.097 .271$ & $\$ 746.653 .823$ \\
\hline Mediana empresa A & $\$ 464.800 .677,00$ & $\$ 555.593 .760$ & $\$ 502.252 .964$ & $\$ 564.053 .257$ & $\$ 561.629 .279$ & $\$ 530.654 .342$ \\
\hline Microempresa & $\$ 68.446 .705,00$ & $\$ 75.186 .176$ & $\$ 81.824 .365$ & $\$ 81.352 .956$ & $\$ 82.829 .489$ & $\$ 80.215 .209$ \\
\hline & $\mathbf{\$ 5 . 0 4 3 . 8 5 9 . 7 1 2 , 0 0}$ & $\mathbf{\$ 7 . 3 6 0 . 3 6 7 . 2 0 1}$ & $\mathbf{\$ 7 . 5 6 3 . 4 8 8 . 7 2 4}$ & $\mathbf{\$ 7 . 0 3 4 . 7 8 7 . 0 2 6}$ & $\mathbf{\$ 6 . 4 7 0 . 3 8 3 . 8 5 4}$ & $\mathbf{\$ 6 . 4 1 3 . 2 8 3 . 0 6 1}$ \\
\hline
\end{tabular}

Fuente: Directorio de Empresas y Establecimientos del INEC

Figura 2. Personal que Trabaja en las Empresas del Sector de la Construcción

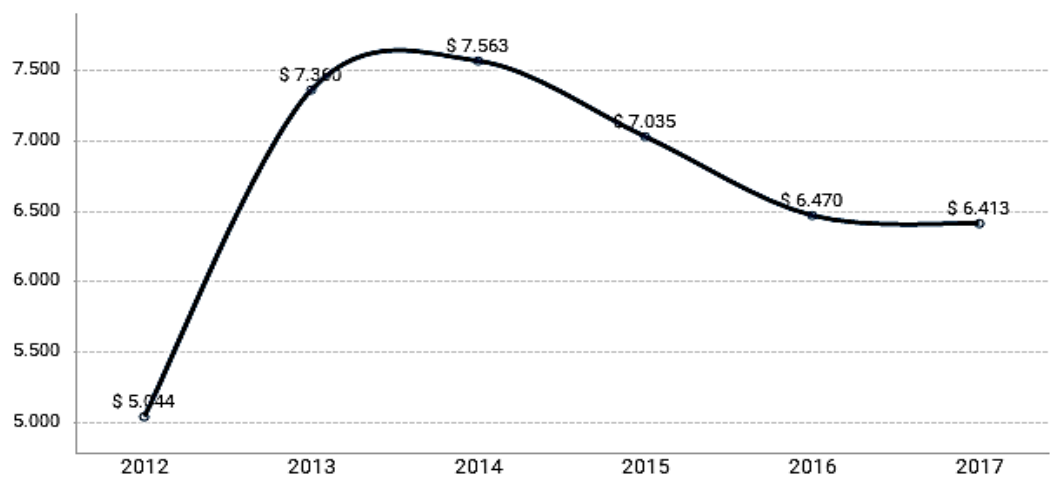

\begin{tabular}{|c|c|c|c|c|c|c|c|c|c|c|c|c|c|c|c|c|c|c|}
\hline Año & 2012 & 2012 & 2012 & 2013 & 2013 & 2013 & 2014 & 2014 & 2014 & 2015 & 2015 & 2015 & 2016 & 2016 & 2016 & 2017 & 2017 & 2017 \\
\hline $\begin{array}{l}\text { Tamaño de } \\
\text { Empresa }\end{array}$ & Hombres & Mujeres & \begin{tabular}{|c|}
$\begin{array}{c}\text { Total de } \\
\text { empleado } \\
\mathrm{S}\end{array}$ \\
\end{tabular} & Hombres & Mujeres & \begin{tabular}{|c|} 
Total de \\
empleado \\
$\mathrm{s}$
\end{tabular} & Hombres & Mujeres & \begin{tabular}{|c|} 
Total de \\
empleado \\
$\mathrm{S}$ \\
\end{tabular} & Hombres & Mujeres & \begin{tabular}{|c|}
$\begin{array}{c}\text { Total de } \\
\text { empleado } \\
\mathrm{s}\end{array}$ \\
\end{tabular} & Hombres & Mujeres & \begin{tabular}{|c|}
$\begin{array}{c}\text { Total de } \\
\text { empleado } \\
\mathrm{s}\end{array}$ \\
\end{tabular} & Hombres & Mujeres & $\begin{array}{c}\text { Total de } \\
\text { empleados }\end{array}$ \\
\hline Grande empresa & 42.264 & 3.613 & 45.877 & 58.097 & 4.899 & 62.996 & 62.175 & 5.304 & 67.479 & 56.832 & 5.239 & 62.071 & 38.623 & 4.782 & 43.405 & 36.290 & 4.345 & 40.635 \\
\hline Pequeña empresa & 33.012 & 4.849 & 37.861 & 35.141 & 5.312 & 40.453 & 36.307 & 5.737 & 42.044 & 34.229 & 5.650 & 39.879 & 31.779 & 5.114 & 36.893 & 30.636 & 5.050 & 35.686 \\
\hline Microempresa & 23.476 & 4.340 & 27.816 & 25.546 & 5.017 & 30.563 & 26.820 & 5.641 & 32.461 & 27.110 & 6.067 & 33.177 & 26.929 & 6.012 & 32.941 & 27.064 & 6.071 & 33.135 \\
\hline Mediana empresa B & 11.527 & 1.102 & 12.629 & 13.828 & 1.345 & 15.173 & 13.734 & 1.548 & 15.282 & 10.980 & 1.501 & 12.481 & 11.335 & 1.234 & 12.569 & 10.329 & 1.440 & 11.769 \\
\hline Mediana empresa A & 11.510 & 1.419 & 12.929 & 12.837 & 1.809 & 14.646 & 10.870 & 1.577 & 12.447 & 12.433 & 1.753 & 14.186 & 10.388 & 1.565 & 11.953 & 9.100 & 1.362 & 10.462 \\
\hline Total & 121.789 & \begin{tabular}{l|l}
15.323 \\
\end{tabular} & 137.112 & 145.449 & $\begin{array}{ll}18.382 \\
\end{array}$ & 163.831 & 149.906 & $\begin{array}{ll}19.807 \\
\end{array}$ & 169.713 & 141.584 & 20.210 & 161.794 & 119.054 & \begin{tabular}{ll|}
18.707 \\
\end{tabular} & 137.761 & 113.419 & 18.268 & 131.687 \\
\hline
\end{tabular}

Podemos visualizar que en el año 2015 con las medidas arancelarias aplicadas en el país el sector de la construcción se vio obligado a desvincular a personas de las diferentes empresas ya que la demanda de los materiales de construcción disminuyó.

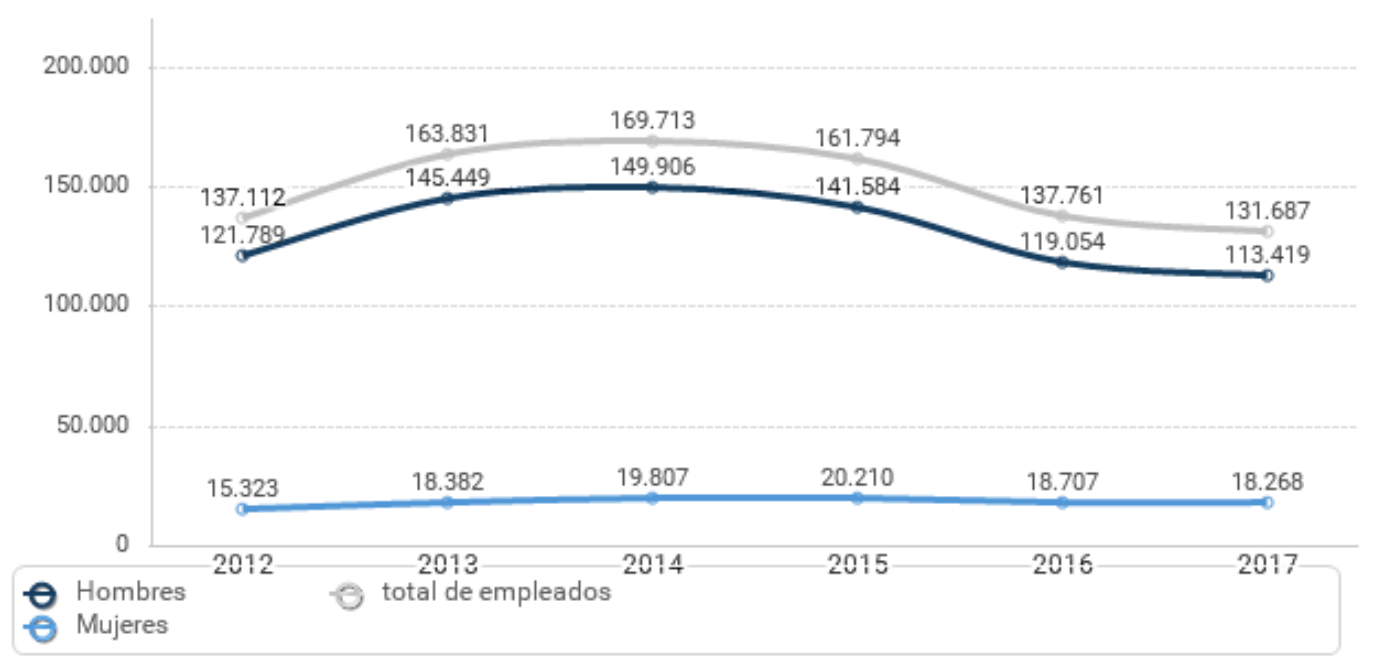


El Ecuador el 30 de marzo de 1983, se publica en el Registro Oficial No. 461, mediante decreto legislativo No. 123, la Ley de Reajuste de Precios, de aplicación en todos los contratos que celebren las entidades del sector público para la construcción de obras. Posteriormente se publica el decreto ejecutivo No. 2059 en el Registro Oficial No. 581 de septiembre 19 de 1983, el cual reglamenta la aplicación de la Ley de Reajuste de precios; y el 16 de Agosto de 1990 la Ley de Contratación Pública y su reglamento el 29 de Abril de 1991 y el 13 de Marzo del 2000, la Ley 2000-4 para la Transformación Económica del Ecuador, leyes que regulan el reajuste de precios de la Obra Pública. decidió aCabe indicar que el Índice de Precios de la Construcción (IPCO), es un indicador que mide mensualmente la evolución de los precios, a nivel de productor y/o importador, de los Materiales, Equipo y Maquinaria de la Construcción, para ser aplicados en las fórmulas polinómicas de los reajustes de precios de los contratos de la Obra Pública, de acuerdo a lo que dispone el Art. 83 de la Ley Orgánica del Sistema Nacional de Contratación Pública vigente a partir del 4 de Agosto del 2008. (el período base es Abril $12 / 2000=100.00)$

De la lista de los productos que se analizan para obtener el índice de precio de la construcción rescatamos los que se consideró más relevante.

Índice de materiales, equipo y maquinaria de la construcción

(Base Abril/12 2000 = 100)

\begin{tabular}{|l|c|c|c|c|c|}
\hline \multirow{2}{*}{ D E N O M I N A C I Ó N } & \multicolumn{3}{|c|}{ INDICES } & \multicolumn{2}{c|}{\begin{tabular}{c} 
VARIACIONES \\
\cline { 2 - 6 }
\end{tabular}} \\
\cline { 2 - 6 } oct-17 & sep-18 & oct-18 & MENSUAL & ANUAL \\
\hline $\begin{array}{l}\text { Aceites, lubricantes, hidraúl y } \\
\text { afines }\end{array}$ & 340,7 & 360,42 & 360,42 & 0 & 5,79 \\
\hline Acero en barras & 244,29 & 247,22 & 248,76 & 0,62 & 1,83 \\
\hline Acero estructural para puentes & 395,98 & 386,64 & 388,75 & 0,55 & $-1,83$ \\
\hline Acetileno & 231,67 & 227,65 & 227,65 & 0 & $-1,74$ \\
\hline $\begin{array}{l}\text { Aditivos para hormigones } \\
\text { asfálticos 3/ }\end{array}$ & 206,43 & 227,54 & 229,05 & 0,66 & 10,96 \\
\hline $\begin{array}{l}\text { Alambres y cables para Inst. } \\
\text { eléctricas }\end{array}$ & 181,75 & 200,97 & 200,97 & 0 & 10,57 \\
\hline $\begin{array}{l}\text { Alambres y cables para Inst. } \\
\text { telefónicas }\end{array}$ & & & & & \\
\hline \multicolumn{1}{|c|}{ Exteriores (I) 2/ } & 177,98 & 179,59 & 182,29 & 1,5 & 2,42 \\
\hline \multicolumn{1}{|c|}{ Interiores } & 217,31 & 259,04 & 259,04 & 0 & 19,2 \\
\hline Alambres de metal & 256,51 & 281,75 & 281,75 & 0 & 9,84 \\
\hline Baldosas de vinil (I) 5/ & 123,69 & 123,69 & 124,42 & 0,59 & 0,59 \\
\hline Artículos de soldadura & 232,02 & 224,66 & 224,66 & 0 & $-3,17$ \\
\hline Ascensores & 126,52 & 130,1 & 129,93 & $-0,13$ & 2,7 \\
\hline Grifería y similares & 278,79 & 278,79 & 278,79 & 0 & 0 \\
\hline $\begin{array}{l}\text { Tubos y Acc.de hierro o acero } \\
\text { galvanizado para instalaciones } \\
\text { eléctricas }\end{array}$ & 234,94 & 223,15 & 223,15 & 0 & $-5,02$ \\
\hline
\end{tabular}

Fuente: Instituto Nacional de Estadísticas y Censo 
¿Estará el mercado siempre en equilibrio? Como hemos visto, Marshall argumentó que no se desviarían tan lejos de los niveles de equilibrio. Con un precio alto, por ejemplo, habría un exceso de oferta y los vendedores podrían beneficiar se de mayores ventas bajando sus precios.

Podemos indicar que por un lado a este sector le afecto la reducción en el precio internacional del petróleo que causó que haya menos recursos disponibles, y eso automáticamente repercutió con una reducción en la demanda. Esta circunstancia, si hubiese sido la única, podía haber servido para que los precios del metro cuadrado se ajusten hacia abajo en una construcción. Pero no fue lo único que afecto al sector de la construcción a esto se le sumo las reformas a las leyes de herencias y plusvalía en el peor momento posible. El efecto de esto fue un frenazo brutal en la demanda de los materiales de construcción y en la demanda de viviendas, ocasionando una disminución en el sector de la construcción y que se vea afectada la balanza comercial del país.

De acuerdo a información obtenida por los entes reguladores gubernamentales indican que hay 540 mil personas registradas en la actividad de la construcción, lo que quiere decir, en empleos directos que ofrece este sector. La industria de la construcción representa el $11 \%$ del Producto Interno Bruto (PIB); y si somos 16 millones de ecuatorianos, ese $11 \%$ se traduce en algo más de 1.7 millones de personas con empleos relacionados a la construcción. Cabe indicar que la mano de obra que se utiliza en el sector de la construcción es no calificada, ya que no se requiere ni siquiera educación primaria para algunas labores, es decir que la construcción absorbe la responsabilidad de generar ingresos para la gente más vulnerable del país.

\section{( V) Variación trimestral porcentual del PIB general y de la}

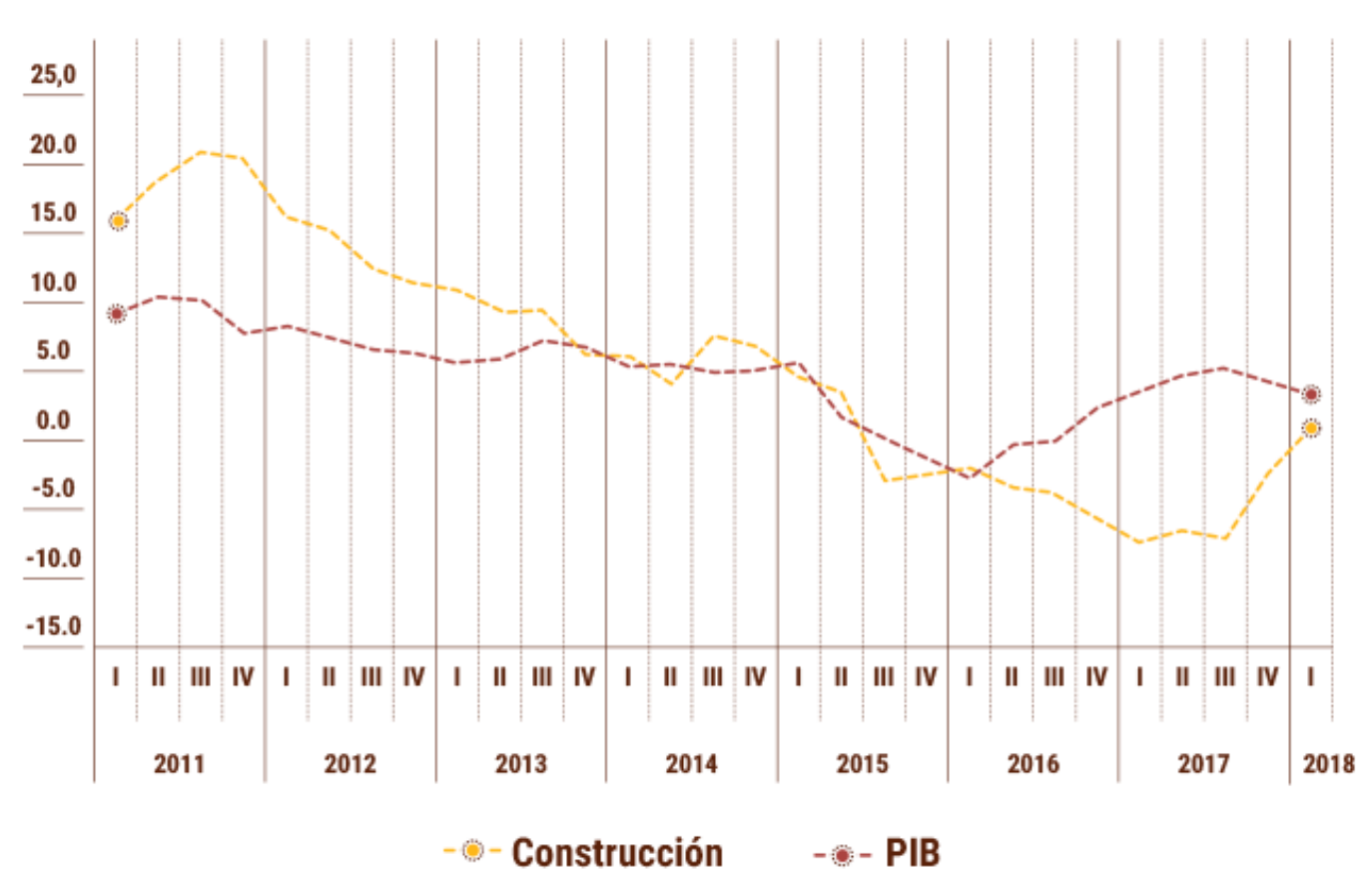


De acuerdo a (Ekos, 2018), en la década pasada, hasta el año 2014 hubo un evidente nivel de desarrollo siendo el año 2011 el de mejor rendimiento con un 17.6\% del PIB. Como se analizó en párrafos anteriores, los niveles de inversión pública crecieron, pero se vieron afectados por la baja del precio del petróleo, lo cual influyó en el financiamiento de las obras previstas con anterioridad.

Las tasas de inversión fueron negativas durante el periodo 2015-2017, lo que afectó a la actividad con un decrecimiento del $-10,51 \%$, generando una depresión en el sector en el periodo 2016-2017, que, de acuerdo al Banco Central, mantendrá una leve recuperación en los próximos años.

Vale recalcar que tuvo mucho que ver la derogatoria de la Ley de Plusvalía, la promulgación de la Ley de Fomento Productivo, que crearon las condiciones de inversión y financiamiento para este sector tan importante de la economía.

\section{Conclusiones.}

- El sector de la construcción crece en consonancia con el PIB, siendo un actor importante dentro de la Economía ecuatoriana. Varios factores son los que pesan en la economía ecuatoriana, principalmente la excesiva dependencia de los ingresos petroleros y la dolarización. Ambos factores, le están situando en un precipicio, que al menor tambaleo le genera inestabilidad. Los altos precios del petróleo le han permitido al Gobierno actual incrementar considerablemente los montos de la inversión pública (construcción de hidroeléctricas, carreteras, centros médicos, centros del buen vivir, unidades educativas del milenio, etc.) y el gasto público, especialmente el corriente. Pero lamentablemente, la bonanza petrolera llegó a su fin, pues los precios de su principal producto de exportación, logran cubrir tan solo los costos de producción.

- De acuerdo al Banco Central, mantendrá una leve recuperación en los próximos años, lo cual tuvo mucho que ver la derogatoria de la Ley de Plusvalía, la promulgación de la Ley de Fomento Productivo, que crearon las condiciones de inversión y financiamiento para este sector tan importante de la economía. que tuvo mucho que ver la derogatoria de la Ley de Plusvalía, la promulgación de la Ley de Fomento Productivo, que crearon las condiciones de inversión y financiamiento para este sector tan importante de la economía.

- Todas estas circunstancias han ayudado a mejorar el desempeño del sector de la construcción, pero la recuperación no es inmediata. La lección es evidente: aplicar medidas que generen mayor confianza en los constructores y en los demandantes.

- Es importante señalar que el Gobierno influye mucho en el desarrollo del sector, el cual implica que deberá tomar medidas para que se encuentre la estabilidad del mismo y despunte paulatinamente, ya que con su recuperación se generará mayor cantidad de empleos sea de manera directa e indirecta, aportando al crecimiento económico del país. 


\section{Referencias Bibliográficas.}

Carl G. Uhr, . W. (1960). Economic Doctrines of Knut Wicksell.

Julián, J. R. (2011). Los errores de la vieja economía. Mexico.

Knight, A. (1971). repensar la revolucion Mexicana. MEXICO.

Mankiw, N. G. (2011). Prinicipios de la Economia. Mexico: Cengage.

Marín, J. (2002). Economia Financiera. Antoni Bosh Editor .

Menger, C. (2007). PRINCIPIOS DE LA ECONOMIA. Unión Editorial.

Mises, L. V. (1995). Liberalismos y Capitalismo . Union Editorial .

Soto, J. H. (2009). Dinero, credito bancario y ciclos economicos . Union Editorial .

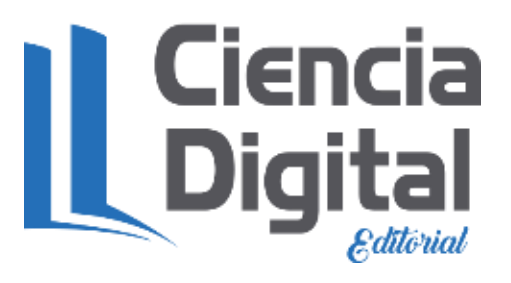




\section{Para citar el artículo indexado.}

Mejía O., Casquete N., Avilés P.\& Parrales C. (2019). Oferta y Demanda en Mercados Competitivos: Enfoque al Sector de la Construcción en el Ecuador. Revista electrónica Visionario Digital 3(2), 143-154. Recuperado desde: http://www.cienciadigital.org/revistascienciadigital/index.php/VisionarioDigital/article/view/3 $\underline{96 / 896}$

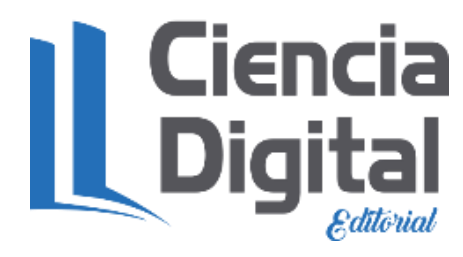

El artículo que se publica es de exclusiva responsabilidad de los autores y no necesariamente reflejan el pensamiento de la Revista Ciencia Digital.

El articulo queda en propiedad de la revista y, por tanto, su publicación parcial y/o total en otro medio tiene que ser autorizado por el director de la Revista Ciencia Digital.
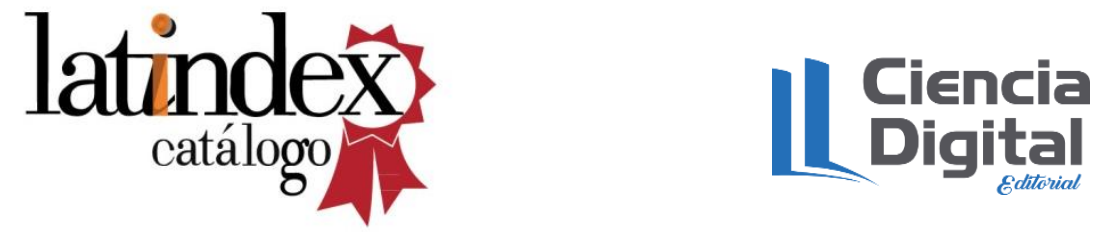